\title{
Offensive Motivation Strategies: The Managerial And Legal Implications
}

Lisa M. Houts, California State University, Fresno, USA

Mark Keppler, California State University, Fresno, USA

Garo Kalfayan, California State University, Fresno, USA

\begin{abstract}
This case study focuses on corporate culture, ethics, employment law, and motivation theory and is appropriate for use in a variety of management classes, such as organizational behavior, human resource management, or ethics. It profiles a lawsuit brought against a company by one of its female employees who was subjected to a variety of "camaraderie building" exercises, including being spanked with a competitor's metal poled yard sign. The case is based on a true story. Only the names and locations have been changed. This case includes actual descriptions of company practices and communications which are offensive and may be disturbing. However, they have been included so that the reader can appreciate the severity of the "motivational practices" that were being employed.
\end{abstract}

Keywords: corporate culture, motivation theory, sexual harassment, ethics, human resource management

\section{INTRODUCTION AND COMPANY BACKGROUND}

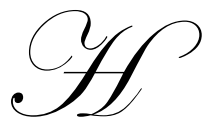

ome Security, Inc. offers residential alarm systems and monitoring services to thousands of customers across the United States. It provides sales, installation, service, and alarm monitoring. Its mission is to become the largest, most trusted, and most successful home security company in the United States.

Since its beginning in 1996, Home Security, Inc. had opened a number of offices to sell and service home security systems. By July 2003, when a Freemont branch office was opened, the company had about 300 employees as well as several remote sales offices. The door-to-door sales force which promoted the company's products and services was young, with most employees between the ages of 18 and 25 .

\section{HOME SECURITY'S MOTIVATIONAL PRACTICES}

In October of 2003, 52-year-old Sandra Rogers was hired as a door-to-door salesperson. Soon she began to witness fellow employees being spanked at work for "motivational purposes." In fact, the company was using spanking, as well as other nontraditional motivational techniques, in both its Baytown and Freemont offices. Competition was encouraged among the sales teams. If performance was not up to par or if unacceptable behavior was committed (e.g., being late to work or talking out of turn at meetings) the employee could choose between being written up or being subjected to an alternate "motivational" consequence at the early morning sales staff meetings. Potential consequences, also referred to as "camaraderie building exercises," included a pie in the face, eating baby food, wearing diapers, singing in front of the group, or most notably being paddled on the buttocks with a competitor's metal yard sign while being jeered at by fellow employees. Those being spanked were instructed to stand at the front of the room with their legs spread in a "police search" position. When female employees were spanked, the atmosphere and language was raucous and lewd. Male employees cheered, encouraged the women to choose spankings instead of being written up, and yelled out crude and sexually inappropriate remarks. Milder examples of these comments included jeers like, "Bend over baby!" and "You've been a bad girl!" Many other coarser jeers used were similar to what might be found in a strip club environment. When men were spanked, the atmosphere was usually quieter and without the lewd commentary. Although Sandra opted for the spankings on three separate occasions, she eventually tried to protest this treatment. She also complained that she was injured by a spanking in January of 2004. 
Sandra eventually left the company in mid-February after approximately five months of employment, saying that she couldn't take any more of Home Security's humiliating "team-building" practices. She said she viewed herself as a mother-figure to her younger team members, and that it was degrading to have to turn around, show her backside to a roomful of young men and women, and get paddled.

\section{THE LAWSUIT AGAINST HOME SECURITY}

Sandra ultimately joined a lawsuit filed by other female employees, including Cynthia, who was paddled so severely in January that she suffered a dark purple bruise on her leg. Cynthia cried after being spanked with a competitor's metal poled yard sign and jeered by managers and coworkers with comments like "Ooh, baby I like that!" and "Getting spanked looks sexy!" Cynthia completed an injury report and went to the doctor. Shortly after her complaint, an investigation was conducted and meetings were called to inform everyone that the spankings were no longer acceptable. At that point, the practice was abandoned. The suit against Home Security alleged sexual harassment, sexual battery, assault, and infliction of emotional distress. The plaintiffs eventually settled out of court, except for Sandra, who asked the jury to award her at least $\$ 1$ million for lost wages, medical costs, and damages.

The attorneys for Home Security used a variety of arguments to justify company practices, including the common defense strategy of "blaming the victim." Supervisors claimed that Sandra was a willing participant in "motivational sales antics," adding that the spankings were not perceived as sexual harassment by the employees, that both men and women were spanked, and that there was no evidence of sexual propositions. To try to undermine Sandra's credibility, they also pointed out that she had filed sexual harassment charges against a previous employer. Furthermore, the company argued that the Freemont office was a rogue operation and that this type of conduct was unique to that office. Other testimony, however, revealed that the Baytown office also engaged in the same types of activities including the spankings.

Before the trial, the chief operating officer (COO) of the company said that he didn't deny that the hazing behavior occurred at the Freemont and Baytown offices, but he claimed that corporate officials were not aware of the behavior until Cynthia complained to the human resources department about her injury. He claimed that as soon as they found out about the spankings the practice was stopped. "We do not condone this kind of behavior, physical touching, harassment or discrimination and we never have," he stated.

Court testimony, however, contradicted the COO's assertions. In fact, both line and staff employees were aware but unconcerned about the office antics, including the spankings and the raunchy corporate culture that had developed. Moreover, certain managers at both the corporate and supervisory levels were actually involved in administering the spankings and saw no problem with it. Men were typically the perpetrators of the spankings, and the male salespeople generally found nothing objectionable about the practice, despite the fact that female recipients of the spankings were unhappy. One might think that the human resources (HR) staff, whose job it was to identify and apply appropriate workplace policies, might have put a stop to the spankings. Unfortunately, the HR director and in-house counsel's opinion was that if there were a problem, it was a worker's compensation problem, not a sexual harassment problem. Thus, many people throughout the organization condoned and even encouraged the rowdy and unusual practices.

Not surprisingly, top management's attempts to show that proper human resource policies were in place at Home Security fell short. The COO, for example, stated in court that Home Security had always had a comprehensive training policy for its employees which made clear the "do's and don't's" for dealing with other employees. While not trying to justify the wrong behavior that took place, he said that those advocating spankings didn't view this behavior as illegal harassment or against company policy. He believed that Home Security had always made a "good faith effort" to train employees and treat them well, and he hoped that would translate into the company being exonerated. The evidence offered at trial, however, showed that despite the COO's claims about adequate employee training, the typical HR training consisted of a five- to 20-minute conference call. Furthermore, employees may have signed the company's sexual harassment policy without having had any instruction on it.

In fact, it was not clear if employees were ever told that hitting coworkers is not acceptable. Indeed, it seems unlikely that this message was clearly conveyed to employees, since an HR analyst at the company testified at 
trial that ". . . spanking is not offensive to me." If the human resources staff, whose specific function is to advise line management about the legality and appropriateness of various employee practices, saw nothing wrong with the spankings, it is doubtful that employees would have fully understood the issue either. Furthermore, regardless of what any written policy or training material may have said, the actions and participation of line managers and HR staff in these practices on a day-to-day basis would have spoken volumes as compared to anything that employees had been told at their brief training session. For example, Diane, the one female supervisor who actively supported the unusual practices believed that going along with spankings was an important part of the corporate culture. In her words, it was "part of blending in with the environment." In fact, the inappropriate behavior was so ingrained in the company's culture that even after the spankings were halted, the reason for doing so was still unclear to Diane. At trial she stated that to her the spankings were "a motivator . . . a way of getting the mood up and getting everyone energized." She went on to say that she didn't see any harm in the practice and would not have stopped if it had been up to her. She contended that the recipients of the spankings didn't show any discomfort or pose any objection, but went along with them, "not putting up a fight at all."

Court testimony, however, showed that Diane's perceptions, like those of many supervisors, were not in line with the employees' actual feelings. Her views were contradicted in court by several saleswomen, including Sandra, who did not find the spankings at all amusing. For example, Rebecca, testified that she was she was pushed up to the front of the room and pressured into opting for a spanking instead of a write-up. She stated that she felt embarrassed and humiliated to be in front of a bunch of jeering men and was also afraid of retaliation if she objected. Coworker Cynthia posed similar objections. She contradicted the Human Resources Director's claim that she had "chosen" the spanking, having felt pushed into it as Rebecca had. Furthermore, Cynthia testified that after that spanking she didn't complain because her managers were aware of and engaging in the spanking. The one time she did approach a supervisor with her concerns, she was discouraged from filing a complaint and was told that she was "a little girl living in a fairyland." She felt that under the circumstances there was no one to whom she could complain and that complaining would be a waste of time. Moreover, she felt she would be singled out, and she feared retaliation that might follow. Sandra herself did attempt to complain about the spankings on several occasions. In one instance, when she was talking to the Freemont office manager and to the vice president (VP) of sales, she was told by the VP that her objections were "stupid" and that everyone was "just having fun!" Unfortunately, she did not put any of her complaints in writing, and the company denied that they had been made.

In sum, the ethical problems at Home Security extended throughout the organization. Testimony showed that corporate managers, including the VP of sales, the marketing manager, and supervisors at the Freemont office, condoned the spankings, and in some cases even administered them. Further, these practices were not deterred by any instructions or advice on the part of HR staff. The lack of proper communication, trust, and appropriate complaint mechanisms at Home Security eventually led to several female employees believing their only recourse was to leave the company and file a lawsuit.

\section{THE VERDICT}

Eventually, a jury of six men and six women found the company guilty of both sexual harassment and sexual battery and awarded Sandra $\$ 1.7$ million dollars. The verdict consisted of the following: Home Security was ordered to pay $\$ 1,000,000$ in punitive damages, $\$ 450,000$ for emotional distress, $\$ 40,000$ in future medical costs, and $\$ 10,000$ in lost wages. In addition, three of the company's former employees were also ordered to pay damages to the defendant because of their personal involvement in the inappropriate conduct. The VP of sales was told to pay $\$ 100,000$ in punitive damages, and Diane and one male supervisor were ordered to pay $\$ 50,000$ each. Sandra reported satisfaction with the reward, and the attorney agreed that it was in the range of what he had expected. Several other female employees, including Cynthia, had previously reached out-of-court settlements with Home Security. The company had offered Sandra a $\$ 150,000$ pretrial settlement, but she rejected it.

When the jury delivered its verdict in April of 2006, Home Security had downsized to only 50 employees, with 40 operating out of the headquarters, and the remainder working as service employees in other outlying offices. All sales positions at the old satellite offices had been eliminated, and the Freemont office had been closed. Although Home Security was still serving 21,000 customers and bringing in monthly revenues of over $\$ 900,000$, the chief financial officer reported that the company's debt had reached $\$ 38.7$ million. In fact, he said that even before the jury award, the company had suffered financial hardship because of the lawsuit. 
In January of 2008, the Freemont Superior Court's decision was reversed by a three-judge appeals court panel on a technicality. The state appeals court was troubled by the instructions given to the jury, saying the main issue should not have been whether or not Sandra was spanked. Instead, the jury should have been told to determine whether she was spanked because she is a woman. This means that Sandra needed to prove that harassment was due to her gender and was not just harassment tinged with sexual connotations. Since both men and women were spanked and administered the spankings, and since the spankings were used as consequences for the same types of actions regardless of gender, the appeals court said that there was no gender-based harassment.

Home Security's counsel hailed the court's reversal as a "great decision." Sandra's attorney was critical of the appellate court's decision, expressing surprise that the court's position seemed to condone "equal opportunity harassment." In other words, if men and women are harassed the same way, then it is okay. He vowed that he would take the case back to trial and was hopeful that the award would be even higher this time. The reality, however, is there may not be much point. A lawyer for Home Security reported that the company is in bankruptcy and that the court battle has exhausted its insurance. After paying out-of-court settlements to the three other female employees, the company has little money left. There may not be much for Rogers to recover even if she did win in a subsequent lawsuit.

The verdict may be open to some debate over the interpretation of what constitutes sexual harassment. Despite the decision from the appeals court, earlier trial evidence seemed to indicate that although both men and women received spankings, they were not treated the same way when the spankings were carried out. At the original trial, Sandra's attorney argued that there was sufficient evidence of harassment based on gender, because witnesses testified about these differences in how the men and women were treated. For instance, one witness said that when a male employee was spanked, they were just told to get up there and get it over with, and the spanking was not accompanied by jeers. By contrast, when a female was spanked, comments like, "Bend over, let me see that a--," or "Spank that b----, slap that ho!" were commonplace. Also, testimony indicated that when women were spanked, men were making all the noise, and the women, with the exception of Diane, were quiet.

Although at this point the outcome is unclear, this case highlights the need for appropriate policies and corporate culture that are correctly conveyed to employees via training and carried out on a day-to-day basis by managers. In addition, it points to the importance of a viable internal complaint system by which employees can air concerns and have them taken seriously. Employers who sanction the type of 'motivational activities' used here create the potential for exactly the type of lawsuit filed by the plaintiffs in this case.

\section{AUTHOR INFORMATION}

Lisa Houts is a lecturer in the Department of Management in the Craig School of Business at California State University, Fresno where she teaches courses in production/operations management, principles of management, and organizational behavior. She has a M.S. in Business from California State University, Fresno.

Mark Keppler is the Executive Director of The Maddy Institute for Public Affairs and a Professor at the Craig School of Business at California State University in Fresno. He has an M.S. in Industrial Relations and a J.D. from the University of Wisconsin. He frequently mediates civil rights and employment disputes with the U.S. Equal Employment Opportunity Commission and arbitrates labor-management disputes for the Federal Mediation and Conciliation Service.

Garo Kalfayan is Chair of the Department of Accountancy at California State University, Fresno. He has a BS in Accounting from UC Berkeley, a J.D. from the UCLA School of Law, and an LL.M. (taxation) from the University Florida, School of Law. He has the following California professional licenses: Law, CPA, and Real Estate Broker.

\section{REFERENCES}

1. Trevino, Linda K. and Katherine A. Nelson, Managing Business Ethics, John Wiley and Sons, Inc., Hoboken, New Jersey, 2004.

2. Jones, Gareth R. and George, Jennifer M., Contemporary Management, Third Edition; McGraw-Hill Higher Education, New York, 2003. 


\section{TEACHING NOTES}

\section{Describe the corporate culture at Home Security. How did this affect the ethical conduct within the organization and the perception and acceptance of the spankings?}

A key job of management is to create a legally and ethically sound environment where people want to work. In this case, management created an environment which some employees, especially the male salespeople and managers, may have found exciting and invigorating, but which other employees found humiliating and degrading. Employees were routinely pressured to accept unusual consequences such as spankings, eating baby food, or wearing diapers, and often complied rather than rocking the boat or being perceived as prudish. There was a high-spirited, "fraternity" type of environment which encouraged bold, unconventional, and sexually charged employee behavior. Most of the sales force was fairly young, ranging from 18-25 years old, and many may have lacked the sophistication or experience to have known better. Many didn't question the company practices at all.

According to Kohlberg, most people are at the conventional level of moral development, which means the way they will determine what is right or wrong is to look at the behavior of those around them for cues. ${ }^{1}$ Even if written rules or policies exist and are emphasized during employee training, which in this case did not happen, the behavior of immediate supervisors or higher levels of management will almost certainly supersede any written or official company policy. Since those in management viewed the spankings as fun, motivational sales antics, many employees in this group of fairly new entrants into the workplace came to see this as acceptable too. While some employees objected, their opinions were generally suppressed, and attempts to complain were ridiculed or minimized by superiors.

It is not a sufficient defense, however, for a company to point to its written policies or training if these are not being lived out in the company during normal business operations. In general, the court will look at actions as determinative. Thus, a company cannot usually win by having a policy that says one thing if day-to-day behavior contradicts it. To protect employees, managers, and the company, it is essential that a well-written company policy manual exists and is clearly communicated to employees and enforced on a day-to-day basis.

\section{Why did management at Home Security choose to use spankings and other unconventional "motivational" techniques with its employees?}

Although Home Security's managers say that the spankings were designed to motivate employees to improve sales or alter other behavior, they had a punitive impact as well. Since employees had to choose between being written up (a punishment) and a spanking, it would stand to reason that the spanking was really an alternate punishment, not a positive way of shaping employee behavior. A key aspect of discipline is that it should be educational, not punitive. In general, it is also best to follow the old adage, "praise in public, punish in private." Spankings conducted in front of coworkers at morning sales meetings would certainly violate that principle.

For whatever reason, some of those employed in both line and staff positions thought that these tactics would be fun and positive. By adhering to these beliefs, they displayed a gross lack of understanding of both current HR law as well as generally accepted norms for professional workplace conduct. If a company wishes to insure that employees at all of its various locations adhere to the same ethics and norms, policy creation must start at the top and expectations must be clearly conveyed to everyone in the organization. Next, managers must "walk the talk" on a day-to-day basis, or else their behavior will supersede company policy, and employees will likely model what they see instead of what they learned during training. In the absence of clearly developed and enforced company policies, managers and even employees in each location may create their own sub-cultures which reflect their own personal level of moral development. These may or may not be in line with company expectations, and may in fact subject the company to extensive problems with employees, perhaps including lawsuits as was the case of Home Security.

\footnotetext{
${ }^{1}$ Managing Business Ethics, Linda K. Trevino and Katherine A. Nelson, John Wiley and Sons, Inc., Hoboken, New Jersey, 2004, p. 115
} 
3. Why didn't more employees complain about the spankings or do something sooner to try to change the practice? Why might employees have chosen spankings or other alternate consequences over being written up, even if they would have actually preferred a write-up?

Just because employees don't complain about a workplace practice doesn't mean that they find it acceptable or appropriate. Many considerations may keep employees from complaining, such as not wanting to be perceived as someone who "rocks the boat," fearing retaliation and job loss, not wanting to get hassled by others, or a belief that the complaint would not be taken seriously. In the case of Home Security, employees also may have fear of social consequences, such as being perceived as "prudish" if they were to object to a practice which seemed acceptable to some of the men and women, including some of those in management. At Home Security, some employees did at first want to be written up, but, after cheering and coaxing from fellow salespeople and managers, ended up choosing the spanking instead. Social pressure was at least in part responsible for causing them to change their minds. This would be consistent with research findings, even as far back as the Hawthorne studies ${ }^{2}$, which revealed that the desire to conform to group norms exceeded people's desire to engage in behavior (i.e., earning more money on a piece rate system) that would be personally more beneficial in other respects. In this case, especially for an older worker such as Sandra, one can speculate that the desire to fit in with the younger crowd for a time surpassed her desire to choose a consequence that seemed more professionally appropriate to the offense she had committed.

4. Why should a company have a safe and viable internal complaint procedure for employees? How might things have transpired differently at Home Security if such a procedure had existed?

A viable internal complaint procedure is an essential element for a company which wishes to maintain an ethical organizational culture as well as protect itself from litigation. Employees need to know that if unfair treatment occurs, there is an ethical ombudsman or a trusted, designated manager, to whom they can go. They need to be able to report the problem without fear of retaliation and with the confidence that their concerns will be taken seriously. In the absence of such a complaint process, employees who feel wronged may feel that their only recourse is to go outside the organization and file a lawsuit, as was the case at Home Security, or to simply quit.

Furthermore, management needs to understand that any time a lawsuit is filed, the company loses, whether the organization is found liable or not. A sexual harassment case that goes to trial often incurs defense costs of at least $\$ 300,000$. If the company loses, it also has to pay damages to the plaintiff as well as the plaintiff's attorney's fees. Thus, the practical side of law, as experienced by many organizations, is that "even when you win you lose." The negative publicity that may accompany a trial, even if the company is cleared, adds to a compelling argument for a viable internal complaint system as well as ethical and properly executed human resource policies.

\section{What constitutes "sexual harassment?" Should Home Security's behavior be considered sexual harassment?}

Sexual harassment is a form of sex discrimination that violates federal civil rights laws. Federal sexual discrimination laws apply to employers with 15 or more employees, including governmental agencies, employment agencies and labor organizations. According to the U.S. Equal Employment Opportunity Commission "unwelcome sexual advances, requests for sexual favors, and other verbal or physical conduct of a sexual nature constitute 'sexual harassment' when this conduct explicitly or implicitly affects an individual's employment, unreasonably interferes with an individual's work performance, or creates an intimidating, hostile, or offensive work environment."

Home Security was clearly covered by federal sexual discrimination laws. The key issues in sexual harassment cases are generally whether the conduct was "unwelcome" and whether the conduct was based on one's gender. While it could be (and was) argued by the company that the conduct was welcome (i.e., no one complained while it was happening) and that it was gender-neutral (i.e., both men and women were spanked), it is clear to see why a jury would find otherwise. Here, female employees were hesitant to complain because such conduct was clearly condoned by management. In addition, the environment in which the spankings occurred (i.e, women being jeered when they were spanked, while employees were mostly silent when the men were spanked), provides some evidence that the company's conduct was not gender-neutral. Looking at the circumstances and the context in which the alleged incidents occurred, as well as the vague language in the law, most juries (like the one here) would likely find that Home Security's behavior constituted sexual harassment.

\footnotetext{
${ }^{2}$ Contemporary Management, Third Edition; Gareth R. Jones and Jennifer M. George, McGraw-Hill Higher Education, New York City, New York, 2003, pp. 55-57.
} 